\title{
Maintenance: An Evolutionary Perspective
}

\author{
Liliane Pintelon and Alejandro Parodi-Herz
}

\subsection{Introduction}

Over the last decennia industrial maintenance has evolved from a non-issue into a strategic concern. Perhaps there are few other management disciplines that underwent so many changes over the last half-century. During this period, the role of maintenance within the organization has drastically been transformed. At first maintenance was nothing more than a mere inevitable part of production, now it is an essential strategic element to accomplish business objectives. Without a doubt, the maintenance function is better perceived and valued in organizations. One could considered that maintenance management is no longer viewed as an underdog function; now it is considered as an internal or external partner for success.

In view of the unwieldy competition many organizations seek to survive by producing more, with fewer resources, in shorter periods of time.To enable these serious needs, physical assets take a central role. However, installations have become highly automated and technologically very complex and, consequently, maintenance management had to become more complex having to cope with higher technical and business expectations. Now the maintenance manager is confronted with very complicated and diverse technical installations operating in an extremely demanding business context.

This chapter, while considering the fundamental elements of maintenance and its environment, describes the evolution path of maintenance management and the driving forces of such changes. In Section 2.2 the maintenance context is described and its dynamic elements are briefly discussed. Section 2.3 explains how maintenance practice have evolved in time and different epochs are distinguished. Further, this sections devotes special attention to describe a common lexicon for maintenance actions and policies to further focuss on the evolution of maintenance concepts. Section 2.4 underlines how the role of the maintenance manager has been reshaped as a consequence of the changes of the maintenance function. Finally, the chapter concludes with Section 2.5 identifying the new challenges for maintenance. 


\subsection{Maintenance in Context}

To discuss the context in which maintenance management is embedded, one may raise the question what is maintenance as such? Most authors in maintenance management literature, one way or another, agree on defining maintenance as the "set of activities required to keep physical assets in the desired operating condition or to restore them to this condition". While this defines what maintenance is about, it may suggest that maintenance is simple, which it is not, as will be confirmed by any maintenance practitioner. Hence "maintenance management" is needed to ingrain maintenance practice in a complex and dynamic context. From a pragmatic view, the key objective of maintenance management is "total asset life cycle optimization". In other words, maximizing the availability and reliability of the assets and equipment to produce the desired quantity of products, with the required quality specifications, in a timely manner. Obviously, this objective must be attained in a cost-effective way and in accordance with environmental and safety regulations. Figure 2.1 clearly shows that maintenance is embedded in a given business context to which it has to contribute. What is more, it shows that the maintenance function needs to cope with multiple forces and requirements within and outside the walls of the organization. Beyond any doubt, the tasks of maintenance are complex, enclosing a blend of management, technology, operations and logistics support elements.

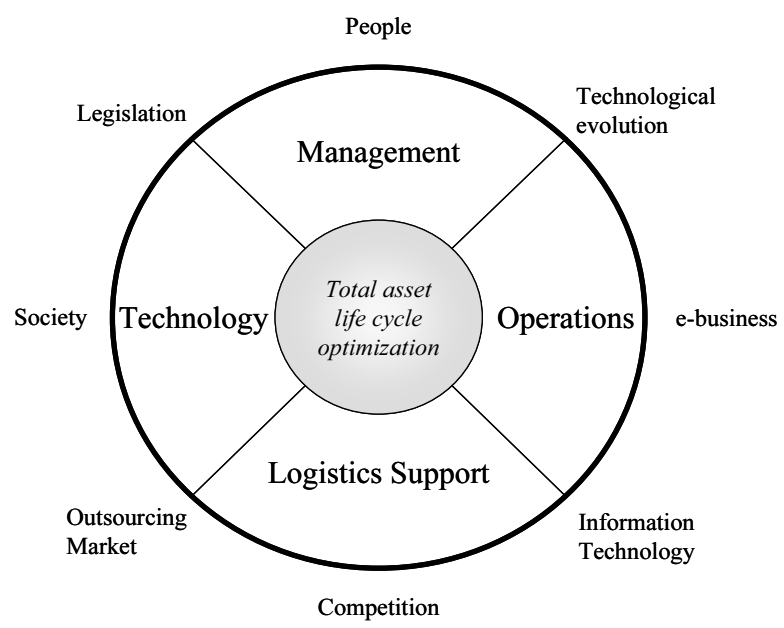

Figure 2.1. Maintenance in context

To cope with and to coordinate the complex and changing characteristics that constitute maintenance in the first place, a management layer is imperative. Management is about "what to decide" and "how to decide". In the maintenance arena, a manager juggles with technology, operations and logistics elements that mainly need to harmonize with production. Technology refers to the physical assets which maintenance has to support with adequate equipment and tools. Operations indicate the combination of service maintenance interventions with 
core production activities. Finally, the logistics element supports the maintenance activities in planning, coordinating and ultimately delivering, resources like spare parts, personnel, tools and so forth. In one way or another, all these elements are always present, but their intensity and interrelationships will vary from one situation to another. For example, the elevator maintenance in a hospital vs. the plant maintenance in chemical process industries stipulates a different maintenance recipe tailored to the specific needs. Clearly, the choice of the structural elements of maintenance is not independent from the environment. Besides, other factors like the business context, society, legislation, technological evolution, outsourcing market, will be important. Furthermore, relative new trends, such as the e-business context, will influence the current and future maintenance management enormously. A whole new era for maintenance is expected as communication barriers are bridged and coordination opportunities of maintenance service become more intense.

\subsubsection{Changes in the Playing Field of Maintenance}

One should expect that neither maintenance management nor its environment are stationary. The constant changes in the field of maintenance are acknowledged to have enabled new and innovative developments in the field of maintenance science.

The technological evolution in production equipment, an ongoing evolution that started in the twentieth century, has been tremendous. At the start of the twentieth century, installations were barely or not mechanized, had simple design, worked in stand-alone configurations and often had a considerable overcapacity. Not surprisingly, nowadays installations are highly automated and technologically very complex. Often these installations are integrated with production lines that are right-sized in capacity.

Installations not only became more complex, they also became more critical in terms of reliability and availability. Redundancy is only considered for very critical components. For example, a pump in a chemical process installation can be considered very critical in terms of safety hazards. Furthermore, equipment built-in characteristics such as modular design and standardization are considered in order to reduce downtime during corrective or preventive maintenance. However, predominantly only for some newer, very expensive installations, such as flexible manufacturing systems (FMS), these principles are commonly applied. Fortunately, a move towards higher levels of standardization and modularization begins to be witnessed at all level of the installations. As life cycle optimization concepts are commendable, it becomes mandatory that at the early design stages supportability and maintainability requirements are well thought-out.

Parallel to the technological evolution, the ever-increasing customer focus causes even higher pressure, especially on critical installations. As customers' service in terms of time, quality and choice becomes central to production decisions, the more flexibility is required to cope with these varying needs. This calls for well-maintained and reliable installations capable to fulfil shorter and more reliable lead-times estimation. Physical assets are ever more important for business success. 
Maintenance does not escape from the (r)evolution in information communication technology (ICT), which has tremendously changed business practices. However, we comment further on this topic in Section 2.3, by illustrating the impact on the role of the maintenance manager as such.

Furthermore, new production and management principles such as Just-in-time (JIT) philosophy, Lean principles, total quality management (TQM) and so forth, have emerged. These production trends intend, by all means, to reduce waste and remove non-value added transactions. It is not surprising that work-in-process (WIP) inventories are one of the key issues for improvement. Clearly, WIP inventories incur high costs as a consequence of the capital immobilization, expensive floor space, etc. As processes happen to be streamlined, WIP inventories are no longer a buffer for problems; accordingly, asset availability and reliability are ever more imperative. Albeit, these principles were initially inspired for production and manufacturing environments are currently also applied and translated in service context.

Above all, the business environment has also changed. Competition has become fierce and worldwide due to the globalization. The latter not only implies that competitors are located all over the world, but also that decisions to move production or service activities from a non-efficient site (e.g. due to high operations and maintenance costs) to another site are quickly taken, even if the other location belongs to another continent. Obviously, with the advent of globalization and intense competitive pressures, organizations are looking for every possible source of competitive advantage. This implies that the nature of business environment has become more complex and dynamic requiring different competitive strategies. Many companies are critically evaluating their value chain and often decide to drastically reorganize it. This results in focusing on the core business. Consequently outsourcing of some non-core business activities and the creation of new partnerships and alliances are being considered by many organizations.

Not surprisingly, maintenance as a support function is no exception for outsourcing. Yet, it may not be so simple. Outsourcing maintenance of technical systems can become a sensitive issue if it is not handled with diligence. Technical systems are unique and situation specific. For example, outsourcing maintenance of utilities or elevators can be relatively straightforward, but when it comes to production floor equipment it can be a strategic issue that has to be handled with extreme care. These circumstances suggest that outsourcing needs to be considered at operational, tactical and strategic level; see Figure 2.2

The simplest, and also the most common, form of outsourcing is "operational outsourcing". At this level, a specific task is outsourced and the relationship between supplier and customer is strictly limited to a sell-buy situation. The impact on the internal organization of the customer is also limited. As outsourcing moves up in the organizational pyramid the relationship between supplier and customer changes and "tactical outsourcing" maybe required. At this level of outsourcing the customer shares management responsibility with the supplier and a simple kind of partnership is established. The impact on the internal organization is also greater. Finally, moving towards the organization's top and for more critical maintenance services, a new form of outsourcing is created, the so-called "strategic outsourcing". This type of outsourcing is also labelled as "transformational out- 
sourcing" because of its impact on the customer's internal organization. Here a complete outsourcing is carried out, the maintenance department is cut away from the customer and moved to the supplier. The relationship between customer and supplier is a strong partnership: the customer has fully entrusted the supplier with one of its strategic maintenance activities. This level of outsourcing is yet less common than the former ones. The rationales of whether or not to outsource maintenance activities are complex and require a well-thought and structured outsourcing process. As mentioned maintenance outsourcing can cover a lot of alternatives. Fortunately, besides, traditional outsourcing of maintenance activities to equipment suppliers or the use of some small local firms, there is nowadays a growing market of medium sized and large outsourcing firms. These firms offer a range of consulting support, specialized services and even full service to allow strategic outsourcing to work.

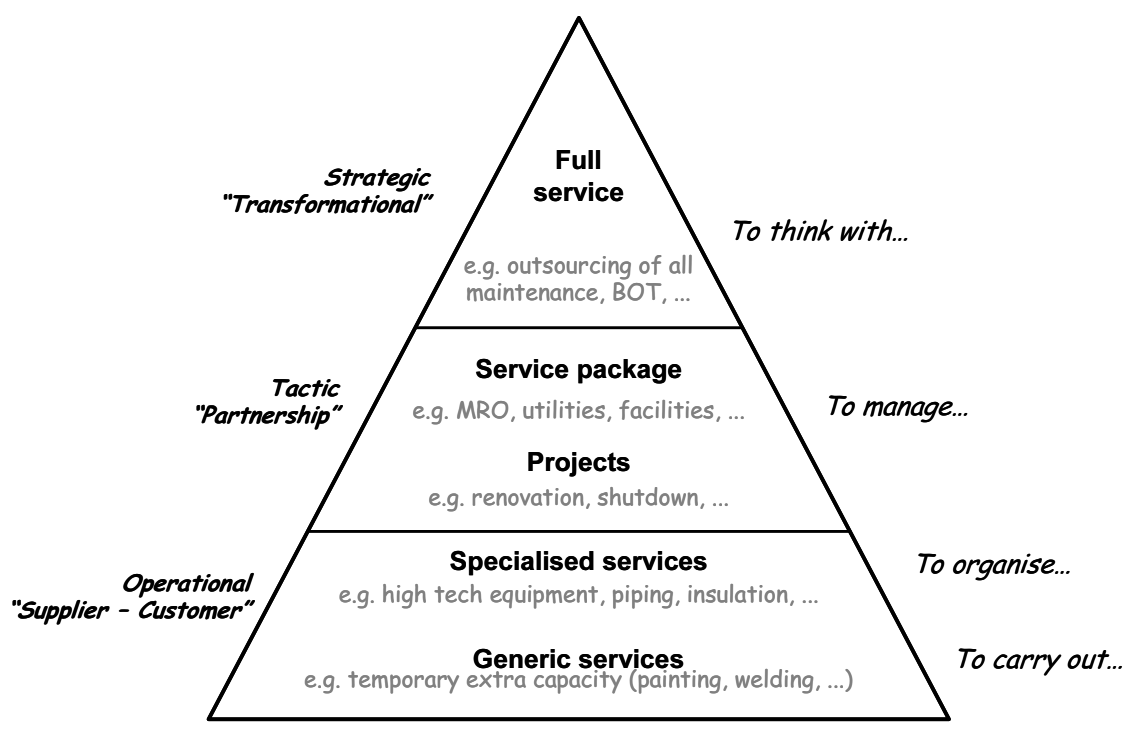

Figure 2.2. Outsourcing decision levels

Societal expectations concerning technology is also creating boundary conditions for maintenance management. The attention paid to sustainability (3P: people, profit, planet) is a clear sign of this. Legislation is getting more and more stringent. This is especially important here because of its impact on occupational safety and environmental standards.

Note that most of the above-mentioned trends for industrial installations can be easily translated to the service sector. Think, for example, of automated warehouses in distribution centre, hospital equipment or building utilities. 


\subsection{Maintenance Practices Over Time}

Consequent to the transformation the maintenance context, the maintenance function has also drastically evolved from a non-issue into a strategic concern (see Figure 2.3). At first maintenance was nothing more than an inevitable part of production; it simply was a necessary evil. Repairs and replacements were tackled when needed and no optimization questions were raised. Later on, it was conceived that maintenance was a technical matter. This not only included optimizing technical maintenance solutions, but it also involved attention of the organization on the maintenance work. Further on, maintenance became a full-blown function, instead of production sub-function. Clearly, now maintenance management has become a complex function, encompassing technical and management skills, while still requiring flexibility to cope with the dynamic business environment. Top management recognizes that having a well thought out maintenance strategy together with a careful implementation of that strategy could actually have a significant financial impact. Nowadays, this has led to treating maintenance as a mature partner in business strategy development and possibly at the same level as production. In turn, these strategies formally consider establishing external partnerships and outsourcing of the maintenance function.

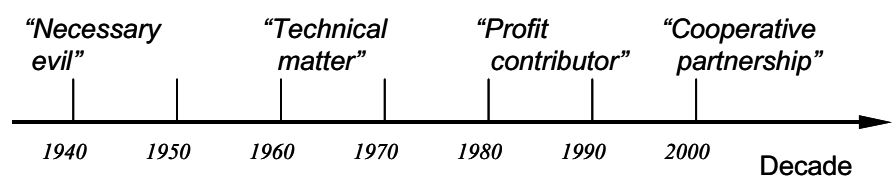

Figure 2.3. The maintenance function in a time perspective

The fact that maintenance has become more critical implies that a thorough insight into the impact of maintenance interventions, or the omission of these, is indispensable. Per se, good maintenance stands for the right allocation of resources (personnel, spares and tools) to guarantee, by deciding on the suitable combination of maintenance actions, a higher reliability and availability of the installations. Furthermore, good maintenance foresees and avoids the consequences of the failures, which are far more important than the failures as such. Bad or no maintenance can appear to render some savings in the short run, but sooner or later it will be more costly due to additional unexpected failures, longer repair times, accelerated wear, etc. Moreover, bad or no maintenance may well have a significant impact on customer service as delivery promises may become difficult to fulfil. Hence, a well-conceived maintenance program is mandatory to attain business, environmental and safety requirements.

Despite the particular circumstances, if one intends to compile or judge any maintenance programme, some elementary maintenance terms need to be unambiguous and handled with consistency. Yet, both in practice and in the literature a lot of confusion exists. For example, what for some is a maintenance policy others refer to as a maintenance action; what some consider preventive maintenance others will refer to as predetermined or scheduled maintenance. Furthermore, some argue that some concepts can almost be considered strategies or philosophies, and 
so on. Certainly there is a lot of confusion, which perhaps is one of the breathing characteristics of such a dynamic and young management science. The terminology used to describe precisely some maintenance terms can almost be taken as philosophical arguments. However, the adoption of a rather simplistic, but truly germane classification is essential. Not intending to disregard preceding terminologies, neither to impose nor dictate a norm, we draw attention, in particular, to three of those confusing terms: maintenance action, maintenance policy and maintenance concept. In the remainder of this chapter the following terminology is adopted.

Maintenance Action. Basic maintenance intervention, elementary task carried out by a technician (What to do?)

Maintenance Policy. Rule or set of rules describing the triggering mechanism for the different maintenance actions (How is it triggered?)

Mainenance Concept. Set of maintenance polices and actions of various types and the general decision structure in which these are planned and supported. (The logic and maintenance recipe used?)

\subsubsection{Maintenance Actions}

Basically, as depicted in Figure 2.4, maintenance actions or interventions can be of two types. They are either corrective maintenance (CM) or precautionary maintenance (PM) actions.

\subsubsection{Corrective Maintenance Actions (CM)}

$\mathrm{CM}$ actions are repair or restore actions following a breakdown or loss of function. These actions are "reactive" in nature; this merely implies "wait until it breaks, then fit it!". Corrective actions are difficult to predict as equipment failure behavior is stochastic and breakdowns are unforeseen. Maintenance actions such as replacement of a failed light bulb, repair of a ruptured pipeline and the repair of a stalled motor are some examples of corrective actions.

\subsubsection{Precautionary Maintenance Actions (PM)}

PM actions can either be "preventive, predictive, proactive or passive" in nature. These types of actions are moderately more complex than the former. To describe fully each one of them, a book can be written on its own. Nonetheless, the fundamental ideas aim at diminishing the failure probability of the physical asset and/or to anticipate, or avoid if possible, the consequences if a failure occurs. Some PM actions (preventive and predictive) are somewhat easier to plan, because they can rely on fixed time schedules or on prediction of stochastic behaviours. However, other types of PM actions become ongoing tasks, originating from the attitude concerning maintenance. Somehow they became part of the tacit knowledge of the organization. Some precise examples of precautionary actions which can be mentioned are lubrication, bi-monthly bearing replacements, inspection rounds, vibration monitoring, oil analysis, design adjustments, etc. All these tasks are considered to be precautionary maintenance actions; however, the underlying principles may be different. 


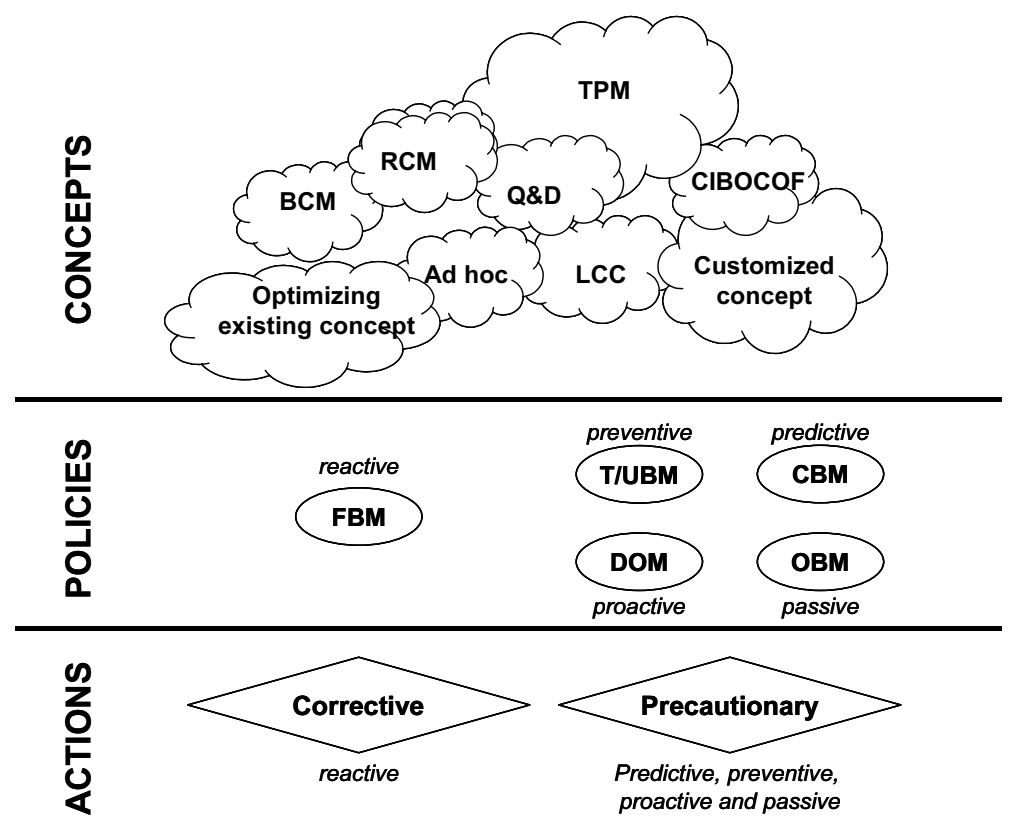

Figure 2.4. Actions, policies and concepts in maintenance ${ }^{1}$

Although it seems a very clear-cut way of defining elementary maintenance interventions, it still may be difficult in practice to assign some interventions to either class. An example here is routine maintenance on medical equipment such as a breathing device. Cleaning and sterilizing this equipment can be called precautionary maintenance since the equipment is not defective at the moment of the intervention. On the other hand, it is very difficult to predict when an intervention will be needed, and this is a typical characteristic of a corrective intervention. Furthermore, even within precautionary maintenance, it is not always simple to classify certain actions into simple types. This is due to the changing perception on maintenance and the fast evolution of its techniques.

\subsubsection{Acuity of Maintenance Actions}

As maintenance knowledge is enhanced and more advance enabling technologies are available, the perception on which maintenance action is "right" has changed a lot during the last decennia. In the 1950s almost all maintenance actions were corrective. Per se maintenance was considered as an annoying and unavoidable cost, which could not be managed. Later on, in the 1960s many companies switched to precautionary (preventive) maintenance programs as they could recognize that some failures on mechanical component had a direct relation with the time or number of cycles in use. This belief was mainly based on physical wear of components or age-related fatigue characteristics. At that time, it was accepted

\footnotetext{
${ }^{1}$ See abbreviations list at the end of this chapter
} 
that preventive actions could avoid some of the breakdowns and would lead to cost savings in the long run. The main concern was how to determine, based on historical data, the adequate period to perform preventive maintenance. Certainly, not enough was known about failure patterns, which, among other reasons, have led to a whole separate branch of engineering and statistics: reliability engineering.

In the late 1970s and early 1980s, equipment became in general more complex. As result, the super-positioning effect of the failure pattern of individual components starts to alter the failure characteristics of simpler equipment. Hence, if there is no dominant age-related failure mode, preventive maintenance actions are of limited use in improving the reliability of complex items. At this point, the effectiveness of applying preventive maintenance actions started to be questioned and was considered more carefully. A common concern about "over-maintaining" grew rapidly. Moreover, as the insidious belief on preventive maintenance benefits was put at risk, new precautionary (predictive) maintenance techniques emerged. This meant a gradual, though not complete, switch to predictive (inspection and condition-based) maintenance actions. Naturally, predictive maintenance was, and still is, limited to those applications where it was both technically feasible and economically interesting. Supportive to this trend was the fact that conditionmonitoring equipment became more accessible and cheaper. Prior to that time, these techniques were only reserved to high-risk applications such as airplanes or nuclear power plants.

In the late 1980 s and early 1990 s a different footprint on maintenance history occurred with the emergence of concurrent engineering or life cycle engineering. Here maintenance requirements were already under consideration at earlier product stages such as design or commission. As a result, instead of having to deal with built in characteristics, maintenance turned out to be active in setting design requirements for installations and became partly involved in equipment selection and development. All this led to a different type of precautionary (proactive) maintenance, the underlying principle of which was to be proactive at earlier product stages in order to avoid later consequences. Furthermore, as the maintenance function was better appreciated within the organization, more attention was paid to additional proactive maintenance actions. For example, as operators are in straight and regular contact with the installations they could intuitively identify and "feel" right or wrong working conditions of the equipment. Conditions such as noise, smell, rattle vibration, etc., that at a given point are not really measured, represent tacit knowledge of the organization to foresee, prevent or avoid failures and its consequences in a proactive manner. Yet these actions are indeed typically not performed by maintenance people themselves, but are certainly part of the structural evolution of maintenance as a formal or informal partner within the organization.

The last type of precautionary (passive) maintenance actions are driven by the opportunity of other maintenance actions being planned. These maintenance actions are precautionary since they occur prior to a failure, but are passive as they "wait" to be scheduled depending on others probably more critical actions. Passive actions are in principle low priority for the maintenance staff as, at a given moment in time, they may not really be a menace for functional or safety failures. However, these actions can save significant maintenance resources as they may reduce the 
number of maintenance interventions, especially when the set up cost of maintenance is high. For example, when maintenance actions are planned or need to be carried out on offshore oil platforms or on windmills in remote locations, getting to the equipment equipment can be costly. Therefore, optimizing the best combination of maintenance actions, at that point in time, is mandatory. This may invoke replacing components with significant residual life that in different circumstances would not be replaced.

\subsubsection{Maintenance Policies}

As new maintenance techniques happen to be available and the economic implications of maintenance action are comprehended, a direct impact on the maintenance policies is expected. Several types of maintenance policies can be considered to trigger, in one way or another, either precautionary or corrective maintenance interventions. As described in Table 2.1, those policies are mainly failure-based maintenance (FBM), time/used-based maintenance (TBM/UBM), condition-based maintenance (CBM), opportunity-based maintenance (OBM) design-out maintenance (DOM), and e-maintenance.

Table 2.1. Generic maintenance policies

\begin{tabular}{|c|c|}
\hline Policy & Description \\
\hline FBM & $\begin{array}{l}\text { Maintenance }(\mathrm{CM}) \text { is carried out only after a breakdown. In case of CFR } \\
\text { behaviour and/or low breakdown costs this may be a good policy. }\end{array}$ \\
\hline TBM / UBM & $\begin{array}{l}\mathrm{PM} \text { is carried out after a specified amount of time (e.g. } 1 \text { month, } 1000 \text { working } \\
\text { hours, etc.). CM is applied when necessary. UBM assumes that the failure } \\
\text { behaviour is predictable and of the IFR type. PM is assumed to be cheaper than } \\
\text { CM. }\end{array}$ \\
\hline CBM & $\begin{array}{l}\text { PM is carried out each time the value of a given system parameter (condition) } \\
\text { exceeds a predetermined value. PM is assumed to be cheaper than CM. CBM is } \\
\text { gaining popularity due to the fact that the underlying techniques (e.g. vibration } \\
\text { analysis, oil spectrometry,...) become more widely available and at better prices. } \\
\text { The traditional plant inspection rounds with a checklist are in fact a primitive } \\
\text { type of CBM. }\end{array}$ \\
\hline OBM & $\begin{array}{l}\text { For some components one often waits to maintain them until the "opportunity" } \\
\text { arises when repairing some other more critical components. The decision } \\
\text { whether or not OBM is suited for a given component depends on the expectation } \\
\text { of its residual life, which in turn depends on utilization. }\end{array}$ \\
\hline DOM & $\begin{array}{l}\text { The focus of DOM is to improve the design in order to make maintenance easier } \\
\text { (or even eliminate it). Ergonomic and technical (reliability) aspects are } \\
\text { important here. }\end{array}$ \\
\hline
\end{tabular}

For the more common maintenance policies many models have been developed to support tuning and optimization of the policy setting. It is not our intention to explain the fundamental differences between these models, but rather to provide an overview of types of policies available and why these have been developed. Much 
has to do with the discussion in the previous section regarding the acuity of maintenance actions. Therefore, it is clear that policy setting and the understanding of its efficiency and effectiveness continues to be fine-tuned as any other management science. We advocate the reader, particularily interested in the underlying principles and type of models, to review McCall (1965), Geraerds (1972), Valdez-Flores and Feldman (1989), Cho and Parlar (1991), Pintelon and Gelders (1992), Dekker (1996), Dekker and Scarf (1998) and Wang (2002) for a full overview on the state-of-the-art literature.

The whole evolution of maintenance was based not solely on technical but rather on techno-economic considerations. FBM is still applied providing the cost of PM is equal to or higher than the cost of CM. Also, FBM is typically handy in case of random failure behaviour, with constant failure rate, as TBM or UBM are not able to reduce the failure probability. In some cases, if there exists a measurable condition, which can signal the probability of a failure, CBM can be also feasible. Finally, a FBM policy is also applied for installations where frequent $\mathrm{PM}$ is impracticable and expensive, such as can be the maintenance of glass ovens. Either TBM or UBM is applied if the CM cost is higher than PM cost, or if it is necessary because of criticality due to the existence of bottleneck installation or safety hazards issues. Also in case of increasing failure behaviour, like for example wear-out phenomena, TBM and UBM policies are appropriate.

Typically, CBM was mainly applied in those situations where the investment in condition monitoring equipment was justified because of high risks, like aviation or nuclear power regeneration. Currently, CBM is beginning to be generally accepted to maintain all type installations. Increasingly this is becoming a common practice in process industries. In some cases, however, technical feasibility is still a hurdle to overcome. Another reason that catches the attention of practitioners in $\mathrm{CBM}$ is the potential savings in spare parts replacements thanks to the accurate and timely forecasts on demand. In turn, this may enable better spare parts management through coordinated logistics support.

Finding and applying a suitable CBM technique is not always easy. For example, the analysis of the output of some measurement equipment, such as advanced vibration monitoring equipment, requires a lot of experience and is often work for experts. But there are also simpler techniques such as infrared measuring and oil analysis suitable in other contexts. At the other extreme, predictive techniques can be rather simple, as is the case of checklists. Although fairly low-level activity, these checklists, together with human senses (visual inspections, detection of "strange" noises in rotating equipment, etc.) can detect a lot of potential problems and initiate PM actions before the situation deteriorates to a breakdown.

At present FBM, TBM, UBM and CBM accept and seize the physical assets which they intend to maintain as a given fact. In contrast, there are more proactive maintenance actions and policies which, instead of considering the systems as "a given", look at the possible changes or safety measures needed to avoid maintenance in the first place. This proactive policy is referred to as DOM. This policy implies that maintenance is proactively involved at earlier stages of the product life cycle to solve potential related problems. Ideally, DOM policies intend to completely avoid maintenance throughout the operating life of installations, though, this may not be realistic. This leads one to consider a diverse set of maintenance requirements at the 
early stages of equipment design. As a consequence, equipment modifications are geared either at increasing reliability by raising the mean-time-between-failures (MTBF) or at increasing the maintainability by decreasing the mean-time-to-repair (MTTR). Per se DOM aims to improve the equipment availability and safety. Some equipment modifications may merely request ergonomic considerations to reduce MTTR, others may need totally new designs. Often DOM projects are combined with efforts to increase occupational safety or increase production capacity, such as set up reduction programs.

A rather passive, but considerably important maintenance policy that needs to be mentioned is OBM. Typically OBM is applied for non-critical components with a relatively long lifetime. For these components no separate maintenance programs are scheduled; maintenance happens if an opportunity arises due to a maintenance intervention for another component of that machine.

More recently in the mid-1990s, with the emergence of the Internet as an enabling technology and the growth of e-business as the standard on business communication, e-maintenance also appeared in the radar of maintenance policies. E-maintenance rather than a policy can also be considered as a means or enabler to some, if not all, the previous policies. However, it is more than just an acronym; it is a step forward to full-integrated maintenance techniques without the boundaries of place. It is in fact a maintenance policy on its own that can support other policies. In particular, academics and practitioners watch with anticipation the great impact it may have on CBM. Conditions measured on site can be remotely monitored, opening entirely new dimensions and opportunities for maintenance services. Therefore, e-maintenance has captured much attention of maintenance researchers given its great impact on business practice. An example of this evolution is telemaintenance, which allows the diagnosis of installation and to perform limited type of repairs from a remote location using ICT and sophisticated control and knowledge tools.

\subsubsection{Maintenance Concepts}

The idea of an "optimized" maintenance program suggests that an adequate mix of maintenance actions and policies needs to be selected and fine-tuned in order to improve uptime, extend the total life cycle of physical asset and assure safe working conditions, while bearing in mind limiting maintenance budgets and environmental legislation. This does not seem to be straightforward, and may require a holistic view. Therefore, a "maintenance concept" for each installation is necessary to plan, control and improve the various maintenance actions and policies applied. A maintenance concept may in the long term even become a philosophy, tenet or attitude to perform maintenance. In some cases advance maintenance concepts are almost considered strategies on their own. What is certain is that maintenance concepts determine the business philosophy concerning maintenance, and that they are needed to manage the complexity of maintenance per se. In practice, it is clear that more and more companies are spending time and effort determining the right maintenance concept.

As a matter of fact, maintenance concepts need to be formulated considering the physical characteristics and the context within which installations operate. Not 
surprisingly, as system complexity is increasing and maintenance requirements are becoming more complex, maintenance concepts will require different levels of complexity. Literature provides us with various concepts that have been developed through a combination of theoretical insights and practical experiences. Choosing and implementing the best concept in a given context is hard. To the question "what concept is best for us?", no short and straightforward answer exists. The right answer to the question is determined by the context, with its complex interaction of technology, business, organization, and so forth. Designing and implementing a good concept will take time and effort. Many companies establish teams with members from different areas (engineering, production, maintenance, ...) to accomplish this difficult task. On the market, many consultants offer their services to assist in this process. This outside help may be very useful to get started and to obtain a better insight into own situation. However, it is useful to note that many consultants have "their" concept (e.g. RCM) they are used to implementing, which may bias their judgment on what concept is "right". Nevertheless, some outside guidance can be useful, but in order to have a good concept that fits all the companies needs, this should be built by in-house people, using all the knowledge available.

Several times in this chapter, it has been suggested that next to increasing systems complexity, maintenance has also evolved in time. This has led to three generations of maintenance concepts with its respective transition points. In the following paragraphs an overview is offered which is also portrayed in Table 2.2.

In the past, equipment was generally much simpler; hence the need for maintenance decision support was moderate. For truly simple systems, even a single maintenance policy may possibly be considered a concept on its own. This is considered the simplest form, the "first generation", of maintenance concepts. Here, only one maintenance policy or even type of action was applied to certain equipment. For a state-of-the-art review on this type of maintenance concepts see Wang (2002). With the advent of automation, installations became highly mechanized and the equipment turned out to be more complex and the interdependencies of the multi-unit systems could no longer be ignored. To maintain such installations efficiently a specific mixture of maintenance policies and actions was required. The need for decision structures became crucial. These circumstances prompted, at first instance, the concept of simple quick and dirty (Q\&D) decision diagrams. Q\&D charts could help to select adequate maintenance policies as only 'yes' or 'no' answers can be given to a series of structured but simple questions. The authors note that even though Q\&D charts lack the holistic view required for well-conceived and sophisticated maintenance concepts, they are still widely used in practice on specific situations thanks to their simplicity. Examples are reported in Pintelon et al. (2000) and Waeyenbergh and Pintelon (2002).

Eventually, superior maintenance concepts were claimed, as the complexity of maintenance decisions increased. As a result, in the last 40 years a vast range of maintenance concepts has been extensively documented in literature. This group of concepts is considered the "second generation" of maintenance concepts and provides a pool of knowledge for maintenance practitioners and researchers. Typical examples, and perhaps the most important ones, are total productive 
maintenance (TPM), reliability-centred maintenance (RCM) and life cycle costing (LCC) approaches.

Table 2.2. Description of the maintenance concepts generations

\begin{tabular}{|c|c|c|c|c|}
\hline Generation & Concept & Description & $\begin{array}{c}\text { Main } \\
\text { strengths }\end{array}$ & $\begin{array}{c}\text { Main } \\
\text { weaknesses }\end{array}$ \\
\hline 1st & Ad hoc & $\begin{array}{l}\text { Implementing FBM and UBM } \\
\text { policies; rarely CBM, DOM, } \\
\text { OBM }\end{array}$ & Simple & $\begin{array}{l}\text { Ad hoc } \\
\text { decisions }\end{array}$ \\
\hline $1 \mathrm{st} \rightarrow 2 \mathrm{nd}$ & Q\&D & $\begin{array}{l}\text { Easy-to-use decision chart. It } \\
\text { helps to decide on the "right" } \\
\text { maintenance policy }\end{array}$ & $\begin{array}{l}\text { Consistent, } \\
\text { Allows for } \\
\text { priorities }\end{array}$ & $\begin{array}{l}\text { Rough } \\
\text { questions, and } \\
\text { answers }\end{array}$ \\
\hline \multirow[t]{3}{*}{ 2nd } & LCC & $\begin{array}{l}\text { Detailed cost breakdown over the } \\
\text { equipment's lifetime helping to } \\
\text { plan the maintenance logistics }\end{array}$ & $\begin{array}{l}\text { Sound basic } \\
\text { philosophy }\end{array}$ & $\begin{array}{l}\text { Resource and } \\
\text { data intensive }\end{array}$ \\
\hline & TPM & $\begin{array}{l}\text { Approach with an overall view } \\
\text { on maintenance and production. } \\
\text { Especially successful in the } \\
\text { manufacturing industry }\end{array}$ & $\begin{array}{l}\text { Considers } \\
\text { human/technical } \\
\text { aspects, fits in } \\
\text { kaizen approach. } \\
\text { Extensive tool box }\end{array}$ & $\begin{array}{l}\text { Time consuming } \\
\text { implementation }\end{array}$ \\
\hline & $\mathrm{RCM}$ & $\begin{array}{l}\text { Structured approach focused on } \\
\text { reliability. Initially developed for } \\
\text { high tech/high risk environment }\end{array}$ & $\begin{array}{l}\text { Powerful } \\
\text { approach, Step- } \\
\text { by-step procedure }\end{array}$ & $\begin{array}{l}\text { Resource } \\
\text { intensive }\end{array}$ \\
\hline 2nd $\rightarrow$ 3rd & RCM-based & $\begin{array}{l}\text { Approaches focused on } \\
\text { remediating some of the } \\
\text { perceived RCM shortcomings } \\
\text { Example: streamlined RCM, } \\
\text { BCM, RBCM }\end{array}$ & $\begin{array}{l}\text { Improved } \\
\text { performance } \\
\text { through } e . g . \text { use of } \\
\text { sound statistical } \\
\text { analysis }\end{array}$ & $\begin{array}{l}\text { Sometimes an } \\
\text { oversimplifi- } \\
\text { cation }\end{array}$ \\
\hline 3rd & Customized & $\begin{array}{l}\text { In-house developed; cherry- } \\
\text { picking from existing concepts } \\
\text { Examples: CIBOCOF, VDM }\end{array}$ & $\begin{array}{l}\text { Exploiting the } \\
\text { company's } \\
\text { strengths and } \\
\text { considering the } \\
\text { specific business } \\
\text { context }\end{array}$ & $\begin{array}{l}\text { Ensuring } \\
\text { consistency and } \\
\text { quality in the } \\
\text { concept } \\
\text { developed }\end{array}$ \\
\hline
\end{tabular}

All these concepts, as many others, enjoy several advantages and are doomed to specific shortcomings. Correspondingly, new maintenance concepts are developed, old ones are updated and methodologies to design customized maintenance concepts are created. These concepts enjoy a lot of interest in their original form and also give raise to many derived concepts. For example, streamlined RCM from RCM. One may consider that customized maintenance concepts constitute the "third generation" of this evolution. They have fundamentally emerged since it is very difficult to claim a "one fits all" concept in the complex and still constantly changing world of maintenance. They are inspired by the former concepts while trying to aviod in the future previously experienced drawbacks. One way or another, customized maintenance concepts mainly consist of a "cherry picking" of useful techniques and ideas applied in other maintenance concepts. This important, but relatively new concept is expected to grow in importance both in practice and with academicians. Concepts that belong to this generation are, for example, value driven maintenance (VDM) and CIBOCOF, which was developed at the Centre of 
Industrial Management (CIB), K.U. Leuven, Belgium. Additionally, in-house maintenance concepts, mostly developed in organization with fairly high maintenance maturity, also belong to this category of concepts. This, for example, was implemented in a petrochemical company that developed a customised concept, which was basically following the RCM logic. However, by extending RCM analysis steps and introducing risk-based inspections (RBI), a more focused and betterconceived maintenance plan could be developed. Moreover, the company borrowed some elements from TPM and incorporated these in their maintenance concept. For example, multi-skilled training programmes were implemented and special tool kits were designed for a number of maintenance jobs using TPM principles.

Before the third generation of maintenance concepts was started, or actually even earlier, they were perceived as necessary. In the literature, a middle step is recognized to bridge the second generation with maintenance concepts such as business-centred maintenance (BCM) and risk based centred maintenance (RBCM) were developed. These concepts are merely RCM-related and still widely applied in many organizations. However, a slow but steady movement towards more customized maintenance concept is expected in the near future, as the maintenance function matures.

Next, a straightforward description on the most important concepts is presented and important references are provided for the interested reader.

\subsubsection{Quick \& Dirty Decision Charts (Q\&D)}

A Q\&D decision chart is a decision diagram with questions on several aspects including; failure paterns, repair behaivours of the equipment, business context, maintenance capabilities, cost structure etc. Answering the questions for a given installation, the user proceeds through the branches of the diagram. The process stops with the recommendation of the most appropriate policy for the specific installation. The Q\&D approach allows for a relatively quick determination of the most advantageous maintenance policy. It ensures a consistent decision making for all installations. Although some Q\&D decision charts are available from literature (e.g. Pintelon et al. 2000), most companies adopting this approach prefer to draw up their own charts, which incorporate their experience and knowledge in the decision process. This can be implemented in several ways. For instance by defining specific questions, adding or deleting maintenance policies, establishing preferred sequence in which the different policies should be considered, etc. This approach however has the drawback of being rough (dirty). The questions are usually put in the basic yes/no format, limiting the answering possibilities. Moreover, answering the questions is usually done on a subjective basis; for example the question whether a given action or policy is feasible is answered based on experience rather than on a sound feasibility study.

\subsubsection{Life Cycle Costing (LCC) Approaches}

LCC originated in the late 1960s and is now resurrecting. The basic principle of LCC is sometimes summarised by "it is unwise to pay too much, but is foolish to spend too little". This refers to the two main underlying ideas of LCC. The first concerns the cost iceberg structure presented by Blanchard (1992) by whom LCC 
was revived. Mainly he proposes that when considering maintenance or equipment purchasing alternatives, one should not be limited to what momentarily can be seen: "the top of the iceberg", such as direct maintenance costs (material, labour, etc.) or the purchase price. The indirectly relevant long run cost such as operational expenses, trainning cost, spares inventory costs, etc. are at least of the same order of magnitude. The second refers to the principle that the further one gets in the design or construction cycle of equipment, the more costly it will be to make modifications (e.g. DOM). Maintenance should be taken into account from the very first moment of designing a machine or system. LCC is a methodology for calculating or estimating the total cost of a system during the entire course of its life. This LCC approach implies a synthesis of costing analysis and engineering design principles that must satisfy life cycle requirements at minimum cost. In turn, design decisions are based on total cost of ownership (TCO) principles.

In the literature, several LCC approaches can be distinguished. Among the more important ones are Terotechnology, Integrated Logistic Support/Logistics Support Analysis (ILS/LSA) and Capital asset management. During the 1970s, the Terotechnology concept originated in the UK and was the first formal attempt towards LCC (Parkes 1970). It describes a total view of maintenance management that combines management, technology, logistical support and financial control for industrial systems. Terotechnology is concerned with the specification and design for reliability and maintainability of physical assets. The application of Terotechnology also takes into account the processes of installation, commissioning, operation, maintenance, modification and replacement. Decisions are influenced by feedback of information on design, performance and cost, throughout the life cycle of a project. Although generally accepted as very useful, it was not until fairly recently that terotechnology or similar LCC was adopted by large-scale industry. This was largely due to the developments in ICT that made LCC easier.

In the 1980s a different LCC-approach, integrated logistic support/logistics support analysis (ILS/LSA), originated in the military logistics support. Maintenance is regarded as an important issue within the integral logistical support. ILS comprises the spectrum of all activities related to the logistical support during its entire life cycle. These logistical support activities refer to maintenance concept development, the spare parts provisioning, the technical information, the maintenance crew, the training programs, etc. The goal of ILS may be summarized as achieving minimum life cycle costs. Furthermore, LSA is an iterative analytical process to identify and evaluate the logistic support for a new system. LSA constitutes the integration and application of various techniques and methods to ensure that supportability requirements are considered in the system design process. Finally, capital asset management, an LCC-approach with real concern of the financial performance of asset, was developed. Capital asset management provides information to make the financial and operational decisions that optimize equipment performance, from deployment through operations, maintenance and retirement. The key focus is not technical, but financial. Asset management aims at maximizing the return on investment (ROI) in capital assets so that they last longer, perform better and cost less to maintain. 


\subsubsection{Total Productive Maintenance (TPM)}

TPM (Takahashi and Takeshi 1990) is much more than just a concept, actually it is even considered a maintenance philosophy, which derives to the greater part of its substance from a variety of non-Japanese management structures and practices, which were adapted by the Japanese to fit their culture. TPM involves total participation, at all levels of the organization. It aims at maximizing equipment effectiveness and establishing a thorough system of preventive maintenance. TPM fits entirely with the TQM philosophy and the JIT approach. The latter makes sure that problems of various nature (material related, breakdown, training related, ...) are tackled and solved one by one, instead of camouflaging them by using large buffer stocks as was the case with MRP approaches. The TPM toolbox consists of various techniques, some of which are universal ones such as 6sigma, Pareto or $\mathrm{ABC}$ analysis, Ishikawa or fishbone diagrams, etc. Other concepts and techniques such as SMED, poke yoke, jidoka, OEE, and the 5S are specific of the TPM philosophy. The last two are of extreme importance and worthy to be explained further. The overall equipment efectiveness (OEE) is a powerful tool to measure the effective use of production capacity. The strength of the concept is the integration of production, maintenance and quality issues into what is called the "six big losses" of useful capacity. Figure 2.5 illustrates this concept. On the other hand, the $5 \mathrm{~S}$ form one of the basic principles of TPM: Seiri (or sorting out), Seiton (or systematic arrangement), Seiso (or Spic and span), Seiketsu (or standardizing) and Shitsuke (or self-discipline).

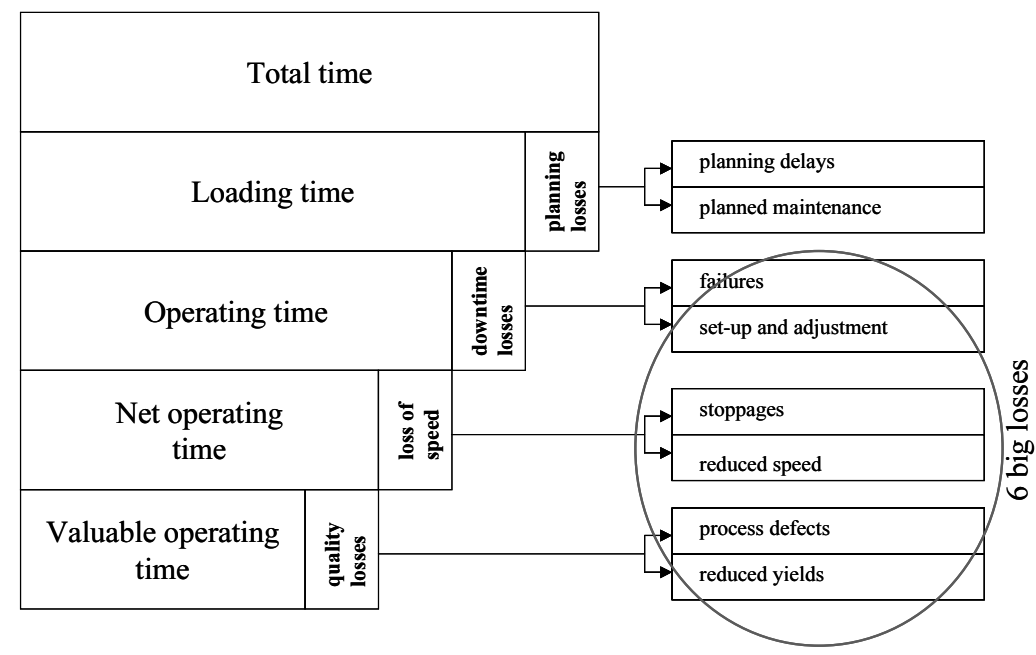

Figure 2.5. The "big six losses" of overall equipment efectiveness

\subsubsection{Reliability Centered Maintenance (RCM)}

RCM originates from the 1960s in North American aviation industry. Later on it was adopted by military aviation, and afterwards it was only implemented at high risk industrial plant such as nuclear power plants. Now it can be found in industry 
at large. Well known are the books by Nowlan and Heap (1978); Anderson and Neri (1990) and Moubray (1997) who contributed to the adoption of RCM by industry.

Note that today many versions of RCM are around, streamlined RCM being one of the more popular ones. However, the Society for Automotive Engineers (SAE) holds the RCM definition that is generally accepted. SAE puts forward the following basic questions to be solved by the any RCM implementation; if any of these is omitted, the method is incorrectly being refered to as an RCM. To answer these seven questions a clear step-by-step procedure exists and decision charts and forms are available:

- What are the functions and associated performance standards of asset in its present operating context?

- How can it fail to fulfil its functions? (functional failures)

- What causes each failure? (failure modes)

- What happens when each failure occurs? (failure effects )

- In what way does each failure matter? (failure consequences)

- What should be done to predict or prevent each failure? (proactive tasks and task intervals)

- What should be done if a suitable proactive task cannot be found? (default actions)

RCM is undeniably a valuable maintenance concept. It takes into account system functionality, and not just the equipment itself. The focus is on reliability. Safety and environmental integrity are considered to be more important than cost. Applying RCM helps to increase the asset's lifetime and establish a more efficient and effective maintenance. Its structured approach fits in the knowledge management philosophy: reduced human error, more and better historical data and analysis, exploitation of expert knowledge and so forth.

RCM is popular and many RCM implementations have started during the last decade. Although RCM offers many benefits, there are also drawbacks. From the conceptual point of view there are some weak points. For instance, the fact that the original RCM does not offer a task packaging feature and thus does not automatically offer a workable maintenance plan and the fact that the standard decision charts and forms offered are helpful but also far from perfect. A serious remark, mainly from the academic side, is about the scientific basis of RCM: the FMEA analysis, which is the heart of the RCM analysis, is often done on a rather ad hoc basis. Often available statistical data are insufficient or inaccurate, there is a lack of insight in the equipment degradation process (failure mechanisms) and the physical environment (e.g. corrosive or dusty environment) is ignored. The balance between valuable experience and equally valuable, objective statistical evidence is often absent. Many companies call in the (expensive) help of consultants to implement RCM; some of these consultants however are not capable of offering the help wanted and this - in combination with the lack of in-house experience with RCM discredits this methodology. RCM is in fact an on-going process, which often causes reluctance to engage in a RCM project. RCM is undoubtedly a very resource consuming process, which also makes it difficult to apply RCM to all equipment. 


\subsubsection{RCM-Related Concepts}

$\mathrm{RCM}$ as such has proven to be a very valuable concept, focussing on reliability and paying attention to safety and environment. Its structured approach ensures asset sustainability. However, there are some drawbacks that should be kept in mind and, if possible, remedied. In the literature one can find many RCM-related concepts such as Gits, Coetzee, BCM, RBCM, streamlined RCM, and so forth. All of them adopt RCM principles with the intention of solving some of its shortcomings. These group of concepts constitute the bridging step to the third generation of maintenance concepts.

Gits (1984) developed an RCM-like maintenance concept. The main difference with the original RCM is the fact that the methodology delivers a workable maintenance plan. The focus of the concept is on technical and organizational aspects, rather than on economic considerations. This three-phase approach establishes the maintenance plan by quantifying and clustering basic maintenance rules. Those rules are harmonised in operational entities that describe what exactly must be done. Later on, Jones (1995) put forward risk based reliability centred maintenance (RBCM), a new variance of basic RCM. Basically, RBCM can be described as RCM, but with a strong statistical background. This tackles and eliminates the drawback of the ad hoc FMEA of the traditional RCM approach. Risk based inspections (RBI) are one of the core concepts here. The RBI methodology enables the assessment of the likelihood and potential consequences of pressure equipment failures. RBI provides companies with the opportunity to prioritize equipment inspections and optimize the inspection methods, frequencies and resources. Furthermore, RBI helps to develop specific equipment inspection plans and enable the implementation of RCM as such. This results in improved safety, lower failure risks, fewer forced shutdowns, and reduced operational costs. The risk-based approach requires a systematic and integrated use of expertise from the different disciplines that affect plant integrity. These include design, materials selection, operating parameters and scenarios, and understanding of the current and future degradation mechanisms and of the risks involved. So far, all preceding RCM inspired concepts aimed at improving technical drawbacks of RCM by coverting them into workable solutions.

It was not until Kelly (1997), with his business-centred maintenance BCM, a full-fledged concept for determining a detailed maintenance plan, that the business as such gained the focal point. Kelly emphasised the importance of identifying, mapping and auditing the maintenance function. The BCM concept also pays attention to the necessary administrative support. Kelly calls his approach a BUTD approach, bottom-up/top-down approach. First, it is a top-down step that starting from the business context, the exact objectives for maintenance are outlined considering all corporate level. The second step is a bottom-up step. It aims at establishing a life maintenance plan for all equipments. In a third and last step, all item life plans are fitted in a maintenance strategy. Applying BCM thus results in a detailed maintenance schedule, ready for use.

RCM implementation is complex, time consuming and is not straightforward. Hence, it should be implemented in a controlled fashion with total support of all levels of the organizations. Coetzee (2002) mentions that RCM is a core methodology to ensure that the organization can achieve world-class results. However, to 
achieve this objective the traditional RCM should be enhanced. Coetzee proposes a “new" RCM blending concept from different RCM authors' related techniques. He also puts forward some innovations like the funnelling approach to ensure that RCM efforts are concentrated on the most important failure modes in the organization.

Finally, there is a vast range of so-called "streamlined RCM" concepts. These concepts claim to be derivations of RCM. It is consultants who mainly promote streamlined RCM as the solution for the resource consuming character of RCM. Although streamlining sounds attractive it should be carefully applied, in order to keep the RCM benefits. Different streamlining approaches exist; however, very few are acceptable as formal RCM methodologies. Based on Pintelon and Van Puyvelde (2006), Table 2.3 provides a picture of popular streamlined RCM approaches.

Table 2.3. Classification of streamlined RCM concepts

\begin{tabular}{l|l|l}
\hline \hline \multicolumn{1}{c|}{ Example } & \multicolumn{1}{|c}{ Characteristics } & \multicolumn{1}{c}{ Pitfalls } \\
\hline \hline $\begin{array}{l}\text { Retro-active } \\
\text { approach }\end{array}$ & $\begin{array}{l}\text { Starts from the existing maintenance } \\
\text { plan. Determines the failure mode } \\
\text { for all maintenance tasks and } \\
\text { implements the last RCM steps for } \\
\text { these. }\end{array}$ & $\begin{array}{l}\text { Quite time-consuming to find the } \\
\text { failure modes for all tasks.Functions" } \\
\text { are detected on ad hoc basis. It Implies } \\
\text { that the existing maintenance plan is } \\
\text { good. }\end{array}$ \\
\hline $\begin{array}{l}\text { Generic } \\
\text { approach }\end{array}$ & $\begin{array}{l}\text { Uses generic lists of failure modes, } \\
\text { or even generic analyses of technical } \\
\text { systems }\end{array}$ & $\begin{array}{l}\text { Ignores the operational context of the } \\
\text { technical systems and the current } \\
\text { maintenance practices. It assumes a } \\
\text { standard level of analysis detail for all } \\
\text { systems. }\end{array}$ \\
\hline $\begin{array}{l}\text { Skipping } \\
\text { approach }\end{array}$ & $\begin{array}{l}\text { Omits one or more steps. Typically, } \\
\text { the first step (functions) is skipped } \\
\text { and the analysis starts with listing the } \\
\text { failure modes. }\end{array}$ & $\begin{array}{l}\text { Omits the first and essential step of } \\
\text { RCM, i.e. the functional analysis and } \\
\text { as such also does not allow for a sound } \\
\text { performance standard setting }\end{array}$ \\
\hline $\begin{array}{l}\text { Criticality } \\
\text { approach }\end{array}$ & $\begin{array}{l}\text { Limits the implementation to critical } \\
\text { functions and/or failures for these a } \\
\text { full RCM analysis is performed. }\end{array}$ & $\begin{array}{l}\text { Often determines criticality on an ad } \\
\text { hoc basis or uses criticality tools } \\
\text { which are less reliable than the RCM } \\
\text { approach }\end{array}$ \\
\hline $\begin{array}{l}\text { Troublemaker } \\
\text { approach }\end{array}$ & $\begin{array}{l}\text { Carries out a full RCM analysis for } \\
\text { critical equipment only. Critical } \\
\text { equipment is defined here as } \\
\text { bottleneck equipment, which had a } \\
\text { lot of maintenance problems in the } \\
\text { past or is critical in terms of safety } \\
\text { hazards. }\end{array}$ & $\begin{array}{l}\text { Idem as above, although here all RCM } \\
\text { steps are followed which guarantees a } \\
\text { complete "picture". }\end{array}$ \\
\hline \multicolumn{2}{|l}{}
\end{tabular}

\subsubsection{Customized Maintenance Concepts}

The value driven maintenance (VDM) methodology proposed by Haarman and Delahay (2004) builds a bridge between traditional maintenance philosophies and the shareholders' value. Not only does VDM simplify the boardroom discussion, it also shows that far from being a cost center, maintenance is actually a major economic value within the overall business performance. It is built on established 
best maintenance practices and concepts such as TPM, RCM and RBI. It shows where the added-value of maintenance lies and how an organisation can be best structured to realise this value. One of the main contributions of VDM is that it offers a common language to management and maintenance to discuss maintenance matters. VDM identifies four value drivers in maintenance and provides concepts to manage by those drivers. For all four value drivers, maintenance can help to increase a company's economic value. VDM makes a link between value drivers and core competences. For each of the core competences, some managerial concepts are provided.

Most recently, Waeyenbergh (2005) presents CIBOCOF as a framework to developed customised maintenance concepts. CIBOCOF starts out from the idea that although all maintenance concepts available from the literature contain interesting ideas, none of them is suitable for implementation without further customization. Companies have their own priorities in implementing a maintenance concept and are likely to go for "cherry picking" from existing concepts. CIBOCOF offers a framework to do this in an integrated and structured way. Figure 2.6 illustrates the steps that this concept structurally goes through. A particularly interesting step is step 5, maintenance policy optimization, where a decision chart is offered to determine which mathematical decision model can be used to optimize the chosen policy (step 4). This decision chart guides the user through the vast literature on the topic.

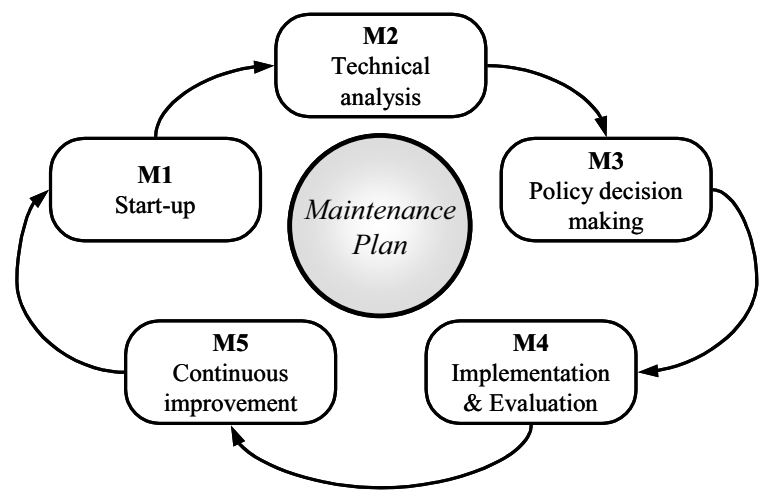

Figure 2.6. CIBOCOF logic

\subsection{Maintenance Manager}

As maintenance management evolved, so did the job of the maintenance manager. Clearly maintenance management is no longer a pure technical function. Business economics (cost-benefit considerations) and business context (how important are the installations in question?, what are the functional requirements?,...) play an important role. A good maintenance manager needs to have a technical background in order to have an eye for the "big picture" and not lose any aspect out of sight. 
Nowadays, the decisions expected from the maintenance manager are complex and sometimes can have far reaching consequences. He/she is (partly) responsible for operational, tactical and strategical aspects of the company's maintenance management. This involves the final responsibility for operational decisions like the planning of the maintenance jobs and tactical decisions concerning the long-term maintenance policy to be adopted. More recently, maintenance managers are also consulted in strategic decisions, e.g. purchases of new installations, design choices, personnel policy, ...

The career path of today's maintenance manager starts out from a rather technical content, but evolves over time into more financial and strategic responsibilities. This career path can be horizontal or vertical. It is also important that the maintenance manager is a good communicator and people manager, as maintenance remains a labor-intensive function. The maintenance manager needs to be able to attract and retain highly skilled technicians. On-going training for technicians is needed to keep track of the rapidly evolving technology. Motivation of maintenance technicians often requires special attention. Job autonomy in maintenance is more than in production, instructions may be vague, immediate assessment of the quality of work is mostly not possible, complaints are more often heard than compliments etc. Aspects like safety and ergonomics are an indispensable element in current maintenance management. Besides people, materials are another important resource for maintenance work. Maintenance material logistics mainly concerns the spare parts management and the determination of finding the optimum trade-off between high spare parts availability and the corresponding stock investments.

The above described evolution in maintenance management incurs a sharp need for decision support techniques of various nature: statistical analysis tools for predicting the failure behaviour of equipment, decision schemes for determining the right maintenance concept, mathematical models to optimize the maintenance policy parameters (e.g. PM frequency), decision criteria concerning e-maintenance, decision aids for outsourcing decisions, etc. Table 2.4 illustrates the use of some decision support techniques for maintenance management. These techniques are available and have proven their usefulness for maintenance, but they are not yet widely adopted.

In the 1960 s most maintenance publications were very mathematically oriented and mainly focussed on reliability. The 1970s and early 1980s publications were more focused on maintenance policy optimization such as determination of optimum preventive maintenance interval, planning of group replacements and inspection modelling. This was a step forward, although these models still often were too focussed on mathematical tractability rather than on realistic assumptions and hypotheses. This caused an unfortunate gap between academics and practitioners. The former had the impression that industry and service sector were not "ready" for their work, while the latter felt frustrated because the models were too theoretical. Fortunately, this is changing. Academics pay more attention to the reallife background of their subject and practitioners discover the usefulness of the academic work. Moreover academic work gets broader and offers a more diverse range of models and concepts, such as maintenance strategy design models, e-maintenance concepts, service parts supply policies, and the like besides the more traditional maintenance optimization models. With the introduction of main- 
tenance software, the necessary data required for these models could be more easily collected. There still is a big gap between practitioners and academics, but it is already slowly closing.

Table 2.4. OR/OM techniques and its application in maintenance

\begin{tabular}{|l|l|}
\hline \hline \multicolumn{1}{|c|}{ Techniques } & \multicolumn{1}{c|}{ Application examples in maintenance management } \\
\hline \hline Statistics & Describing failure behaviour \\
Markov theory & Reliability prediction of complex systems \\
Renewal theory & Availability studies of repairable systems \\
Math programming & Replacement decisions (group or individual) \\
Decision theory & Maintenance policy parameter optimization \\
Queueing theory & Decisions under uncertainty \\
Simulation & Trade-off personnel capacity - service level \\
Inventory control & Comparison of alternative maintenance policies \\
Time and motion study & MRO management: FMI, NMI, SMI and VSMI \\
Scheduling - rostering & Estimation of maintenance intervention times \\
Project planning & $\begin{array}{l}\text { Daily planning of maintenance jobs } \\
\text { MCDM }\end{array}$
\end{tabular}

The help from information technology (IT) is of special interest when discussing decision support for maintenance managers. Computerized maintenance management systems (CMMS), also called computer aided maintenance management (CAMM), maintenance management information systems (MMIS) or even enterprise asset management systems (EAM), nowadays offer substantial support for the maintenance manager. These systems too have evolved over time (Table 2.5). IT of course also supports the e-maintenance applications and offers splendid opportunities for knowledge management implementations. At the beginning of the knowledge management hype, knowledge management was mainly aimed at fields like R\&D, innovation management, etc. Later on the potential benefits of knowledge management were also recognized for most business functions. For maintenance management, a knowledge management programme helps to capture the implicit knowledge and expertise of maintenance workers and secure this information in information systems, so making it accessible for other technicians. The benefits of this in terms of consistency in problem solving approach and knowledge retention are obvious. Other knowledge management applications can be, for example, expert systems, assisting in the diagnosis of complex equipment 
failures, or data mining on maintenance history records to learn about failure causes. A knowledge management programme will also help to keep track of individual skills and expertise and as such support personnel management over time.

Table 2.5. Evolution of CMMS

\begin{tabular}{|c|c|c|}
\hline $\begin{array}{c}\text { Business IT } \\
\text { systems }\end{array}$ & CMMS & Characteristics \\
\hline$\frac{2}{2}$ & 1st generation & $\begin{array}{l}\text { Mainly registration and data administration (EDP). } \\
\text { Limited or no process support. } \\
\text { Low priority mainframe applications. } \\
\text { Limited software market, a lot of in-house development. }\end{array}$ \\
\hline $\begin{array}{l}\frac{2}{2} \\
2 \\
\frac{1}{2} \\
\infty \\
2 \\
2\end{array}$ & 2nd generation & $\begin{array}{l}\text { Cost control and work order management; } \\
\text { MRO management most often included, ... } \\
\text { Link with company's financial information module. } \\
\text { First MIS for maintenance } \\
\text { Many stand-alone microcomputer applications. } \\
\text { Dynamic, but not always reliable, software market. }\end{array}$ \\
\hline $\begin{array}{c}\vdots \\
\stackrel{2}{2} \\
2\end{array}$ & 3rd generation & $\begin{array}{l}\text { Broader, e.g. also asset utilization, and EHS module } \\
\text { External communication possible, e.g. e-MRO. } \\
\text { Enhanced analytical capabilities. } \\
\text { Multimedia and web enabled features. } \\
\text { Matured market for embedded (part of e.g. ERP) or BoB. }\end{array}$ \\
\hline
\end{tabular}

Clearly, the evolution in maintenance management offers a challenging job environment for today's maintenance manager. This maintenance manager needs to be aware of "the big picture", i.e. the business context and the maintenance organization as a whole. Moreover, he/she needs to have a sound technological background and be prepared to keep informed of technological evolutions. The maintenance manager needs real management skills, to manage the resources personnel and materials - in an efficient and effective way, while keeping asset utilization and asset life cycles in mind. Growing in the function of maintenance manager, will also mean acquiring new skills, e.g. in financial management. Last but not least, today's maintenance manager needs to be flexible, flexible to face threats and to grab opportunities in today's dynamic business environment where increasing globalisation, many mergers and acquisitions, growing outsourcing markets and emerging e-maintenance technologies are part of daily life.

\subsection{Conclusions and New Challenges of Maintenance}

Maintenance management undoubtedly has undergone major changes during the past decade. It has moved from being low profile, necessary but difficult to manage problems, to be regarded a prominent business function, an important element in business strategy. Not only practitioners have changed their mind about maintenance; academics did as well. Maintenance nowadays is a professional business 
function and an area of intensive academic research. Efforts are aimed at advancing towards world class maintenance and providing methodologies to do so. Pintelon et al. (2006) describes several maintenance maturity levels required to achieve world class maintenance; these are illustrated in Figure 2.7.

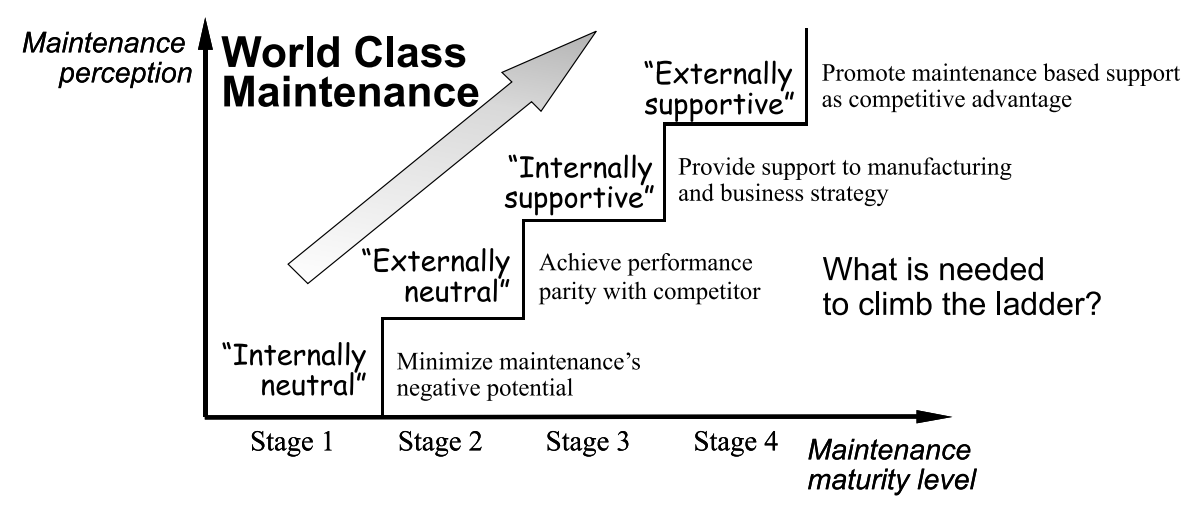

Figure 2.7. Maturity levels of maintenance

Maintenance concept optimization has professionalized. Corrective and precautionary actions are combined in different policies, from reactive to preventive and from predictive to proactive policies. A sound insight into the pros and cons of each of these policies is available in practice and research supports the selection and optimization of these policies. These policies are no longer ad hoc and lose elements within maintenance management but policies are also embedded in maintenance concepts, focussing on reliability and productivity. These concepts ensure consistent decision making for all equipment and at the same time allow for individualized installation maintenance concepts. Decision tools are available to support this process.

Top management nowadays, at least in most companies, recognizes the importance of maintenance as an element of their business strategy. Expectations for maintenance are no longer formulated as "keep things running", but are based upon the overall business strategy. This strategy can be based on flexibility, quality and low cost. The maintenance organization, with its structural and infrastructural elements, is built accordingly.

The previous paragraph may give the impression that all problems for maintenance management are already solved; this however is not the case. New opportunities in terms of, for example, outsourcing and e-maintenance exist. Moreover, there is a threatening gap between the top management level and the overall maintenance strategy determination and the tactical level on which the maintenance concepts are designed, detailed and implemented (Figure 2.8). The gap, however, is there between the alignment of the tactical and subsequent operational phase on the one hand and the strategic phase on the other. While both aspects are well studied, the link between the two is often not well established. This leads to disappointments with top management as well as frustration with maintenance managers. Research shows a similar gap. There is some - though 
still not enough - research on the link between maintenance and business strategy. The main focus of maintenance management research is still on the tactical and operational planning. Links between the former and the latter part of research however are still very rare. Closing this gap by linking maintenance and business throughout all decision levels is one of the major challenges for the future; every step taken brings us closer to real world-class maintenance.

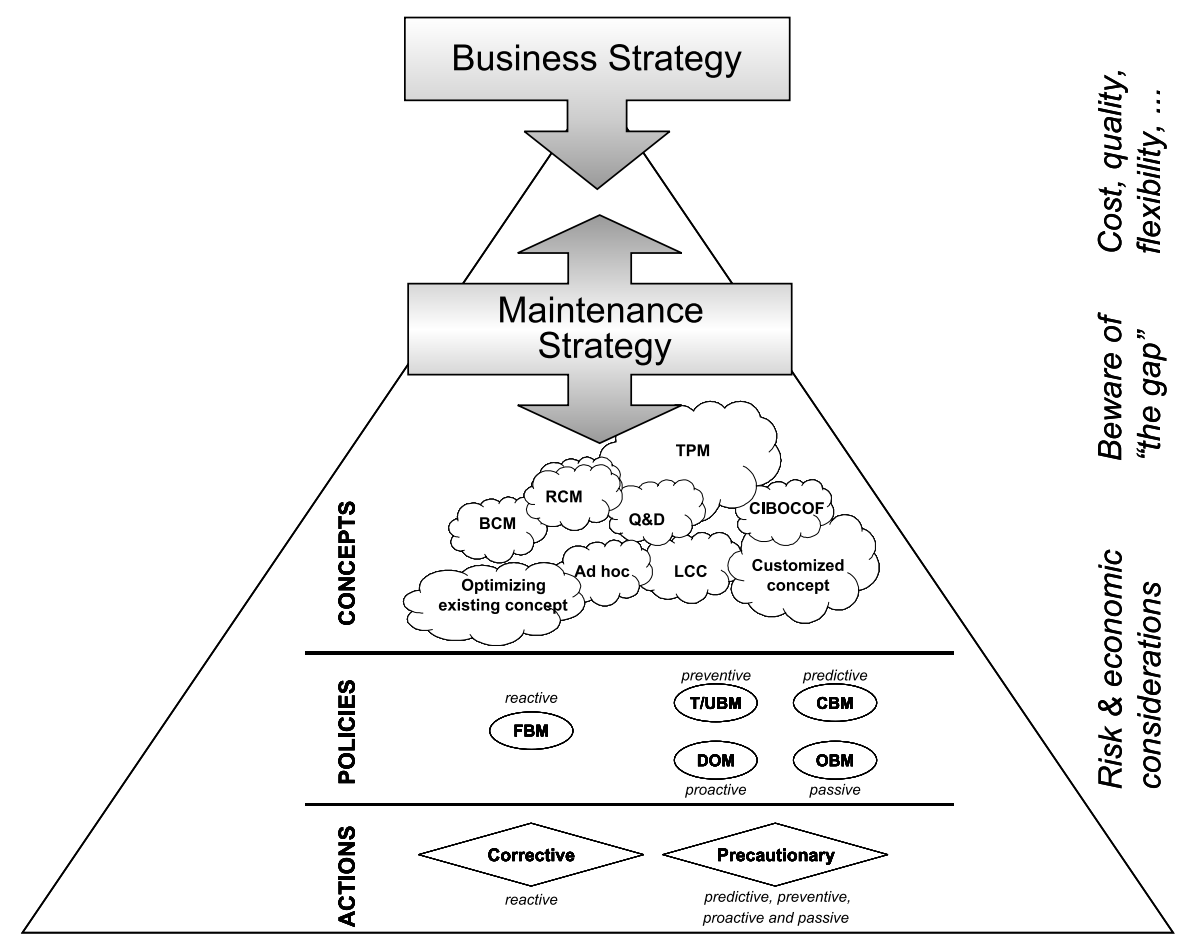

Figure 2.8. Gap between maintenance and business strategy

\subsection{List of Abbreviations}

BCM: Business-centred maintenance

BoB: Best-of-breed

BUTD: Bottom-up/top-down analysis

CAMM: Computer aided maintenance management

CBM: Condition-based maintenance

CFR: Constant failure rate
CIBOCOF: Center Industrieel Beleid Onderhoudsontwikkelingsframework CM: Corrective maintenance

CMMS: Computerized maintenance management systems

DOM: Design-out of Maintenance DSS: Decision support systems 
EAM: Enterprise asset management (system)

EHS: Energy, health and safety

EDP: Electronic data processing

EUC: End user computing

FBM: Failure-based maintenance

FMEA: Failure modes and effect analysis

FMI: Fast moving items

FMS: Flexible manufacturing systems

GUI: Graphical user interface

ICT: Information communication technology

IFR: Increasing failure rate

ILS: Integrated logistics support

IT: Information technology

JIT: Just-in-time

LCC: Life-cycle costing

LSA: Logistics support analysis

MCDM: Multi-criteria decisionmaking

MIS: Management information systems

MMIS: Maintenance management information system

MRO: Maintenance repair and operating supplies
MTBF: Mean-time-between-failures

MTTR: Mean-time-to-repair

NMI: Normal moving items

OBM: Opportunity-based maintenance

OEE: Overall equipment effectiveness

OM: Operations management

OR: Operations research

PM: Precautionary maintenance

Q\&D: Quick \& dirty decision charts

R\&D: Research \& development

RBI: Risk-based inspections

RCBM: Risk-based centred maintenance

RCM: Reliability-centred maintenance

ROI: Return on investment

SAE: Society of automotive engineering

SMED: Single minute exchange of dies

SMI: Slow moving items

TBM: Time-based maintenance

TCO: Total cost of ownership

TPM: Total productive maintenance

TQM: Total quality management

UBM: Use-based maintenance

VDM: Value-driven maintenance

VSMI: Very slow moving items

WIP: Work in progress

\subsection{References}

Anderson, R.T., Neri, L., (1990), Reliability Centred Maintenance: Management and Engineering Methods, Elsevier Applied Sciences, London

Blanchard, B.S., (1992), Logistics Engineering and Management, Prentice Hall, Englewood Cliffs, New Jersey

Cho, I.D, Parlar, M., (1991), A survey on maintenance models for multi-unit systems. European Journal of Operational Research, 51:1-23

Coetzee, J.L., (2002), An Optimized Instrument for Designing a Maintenance Plan: A Sequel to RCM. PhD thesis, University of Pretoria, South-Africa

Dekker, R., (1996) Applications of maintenance optimization models: A review and analysis. Reliability Engineering and System Safety, 52(3):229-240

Dekker, R., and Scarf, P.A., (1998) On the impact of optimisation models in maintenance decision making: the state of the art. Reliability Engineering and System Safety, 60:111-119

Geraerds, W.M.J., (1972), Towards a Theory of Maintenance. The English University Press. London. 
Gits, C.W., (1984), On the Maintenance Concept for a Technical System: A Framework for Design, Ph.D.Thesis, TUEindhoven, The Netherlands

Haarman, M. and Delahay, G., (2004), Value Driven Maintenance - New Faith in Maintenance, Mainnovation, Dordrecht, The Nederlands

Jones, R.B., (1995), Risk-Based Maintenance, Gult Professional Publishing (Elsevier), Oxford

Kelly, A., (1997), Maintenance Organizations \& Systems: Business-Centred Maintenance, Butterworth-Heinemann, Oxford

McCall, J.J. (1965), Maintenance policies for stochastically failing equipment: A survey. Management Science, 11 (5):493-524

Moubray, J., (1997), Reliability-Centred Maintenance. Second Edition. ButterworthHeinemann, Oxford

Nowlan, F.S., Heap, H.F., (1978), Reliability Centered Maintenance, United Airlines Publications, San Fransisco

Parkes, D. in Jardine, A.K.S., (1970), Operational Research in Maintenance, University of Manchester Press, Manchester

Pintelon, L., Gelders, L., Van Puyvelde, F., (2000), Maintenance Management, Acco Leuven/ Amersfoort

Pintelon, L., Gelders, L., (1992) Maintenance management decision making. European Journal of Operational Research, 58:301-317

Pintelon, L., Pinjala, K., Vereecke, A., (2006), Evaluating the Effectiveness of Maintenance Strategies, Journal of Quality in Maintenance Engineering (JQME), 12(1):214-229

Pintelon, L., Van Puyvelde, F., (2006), Maintenance Decision Making, Acco, Leuven, Belgium

Takahashi, Y. and Takashi, O., (1990) TPM: Total Productive Maintenance. Asian Productivity Organization, Tokyo

Valdez-Flores, C., Feldman, R.M., (1989) A survey of preventive maintenance models for stochastically deteriorating single-unit systems. Naval Research Logistics, 36:419-446

Waeyenbergh, G., (2005), CIBOCOF - A Framework for Industrial Maintenance Concept Development, $\mathrm{PhD}$ thesis, Centre for Industrial Management - K.U.Leuven, Leuven, Belgium

Waeyenbergh, G., Pintelon, L., (2002) A framework for maintenance concept development. International Journal of Production Economics, 77:299-313

Wang H., (2002), A survey of maintenance policies of deteriorating systems. European Journal of Operational Research, 139:469-489 